\title{
Employee Background Verification: The Cross-Referencing Effect
}

\author{
Carole Bonanni, (Email: carol.bonanni@ucfv.ca), University College of the Fraser Valley and Simon Fraser University, Canada \\ Dean Drysdale, Kwantlen University College, Canada \\ Andrea Hughes, Simon Fraser University, Canada \\ Patrick Doyle, Simon Fraser University, Canada
}

\begin{abstract}
Pre-employment screening has increased in recent years. This paper examines the effects of four pre-employment screening tools (reference interviews, criminal record checks, credit bureau investigations, and education verifications) in identifying negative indicators about job applicants. More specifically this investigation identifies, for a Canadian organization, the percentage of negative indicators that were uncovered by each screening tool as well as the percentage of negative indicators that were uncovered through the use of combinations of screening tools. The percentages have been found to be in line with the data already available for American organizations. The main contribution of this research however is to show that when various screening tools are used in conjunction they have a greater potential to uncover applicants' negative histories through a synergistic process termed 'cross-referencing'. The results indicate that cross-referencing increases the rate at which negative indicators are found in reference interviews by up to $10 \%$.
\end{abstract}

"Hiring a new employee is like a box of chocolates: you never know what you are going to get" (USA Today, Dec 1996, page 10)

\section{INTRODUCTION}

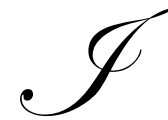

n today's knowledge economy, human capital is perceived as a critical asset that helps a firm build its competitive advantage. In this context, it is critical for firms to hire both the best candidates and also to avoid bad hires. Firms are therefore increasingly using a battery of pre-employment tools such as multiple interviews, psychometric testing, behavioural testing and background screening to make the best informed hiring decision. Background screening is the most commonly cited tool used to avoid poor hiring decisions (Adler, 1993; Wang \& Kleiner, 2004; Mesenbrink, 2002).

Pre-employment background screening presents the following three advantages:

- It limits the uncertainty in the hiring process (Rosen, 2002). Background screening takes place once the person has been interviewed and the firm is interested in hiring the candidate: Frankenfield \& Kleiner (2000) suggested that a comprehensive pre-employment screening process could reduce the applicant pool by up to $60 \%$. and consequently reduce the probability of making a poor or negligent hiring decision (Adler, 1993; Wang \& Kleiner, 2004)

- A screening program can also protect against lawsuits as it shows that the company has exercised due diligence (Rosen, 2002).

- $\quad$ Publicizing that the company conducts background screening will deter an applicant with a questionable past from applying (Rosen, 2002; Vinik, 2005)

There are both direct and indirect costs resulting from negligent hiring. Direct costs include theft, assault, fraud, and negligent hiring lawsuits. These costs can be quite high. For example in the US, increasingly the courts are holding firms accountable for what they "knew or should have known" had a background check been conducted (Adler, 1993; Le \& Kleiner, 2003). Average settlement costs for negligent hiring in the United States range from 
$\$ 1,000,000$ to $\$ 1,600,000$ (Hight \& Raphael, 2003). The costs associated with a bad hire are generally estimated to be at least two times the employee's annual compensation through costs such as turnover, theft, lower productivity and morale, and lost customers through poor service (Wang \& Kleiner, 2004). Sanford (2005) argues that these costs are usually significantly greater for more senior positions. Indirect costs include, for example, the costs incurred due to unmotivated employees, unknowledgeable employees, or poor morale ((Wang \& Kleiner, 2004; Sanford, 2005)).

Studies identify the benefits of background screening as decreased turnover and theft, and improved organizational performance and employee morale (Keller, 2004; Sandford, 2005; Wang \& Kleiner, 2004.)

This paper examines the percentage of applicants in Canada who are found to have negative indicators in their personal or professional histories by looking at the different screening tools individually. It also attempts to identify synergies which result from using various combinations of tools.

Section one reviews the various pre-employment screening tools. Section two describes the dataset. Section three measures the cross-referencing effect. Section four concludes this paper by emphasizing the contribution, limitation and future direction of this research

\section{DESCRIPTION OF THE VARIOUS CATEGORIES OF BACKGROUND SCREENING TOOLS}

Typical background screening tools are reference interviews, criminal record checks, credit bureau investigations, and education verifications (Hight \& Raphael 2003; Adler, 1993; Wiggins, 1998). Other screening tools that are used, predominantly in the United States, include drug tests, driver's license records, and Worker's Compensation claims (Philbrick, Bart, Sparks, \& Hass, 1999; Adler, 1993). Each screening tool has two possible outcomes; they can either be 'clear', or 'not clear'. A 'not clear' rating is a signal that a manager might want to use caution or request additional information before making the final hiring decision, it is not a definite indication that the applicant should not be hired.

Current studies on the percentage of applicants who are found to be 'not clear' through background checks have produced wide-ranging results. These studies have found that $25 \%$ to $80 \%$ of job applicants lie, exaggerate, or conceal relevant information during the pre-employment screening process (Hight \& Raphael, 2003; Philbrick, Bart, Sparks, \& Hass, 1999; Wang \& Kleiner, 2004; Sloane, 1991). This includes, but is not limited to, exaggerated positions, dates of employment, and education credentials, or concealed criminal histories. Below we describe each of the four main screening tools: reference check, criminal record check, credit-bureau investigation and education verification.

\section{Reference Check}

A 'clear' rating for a reference interview means that no claims or statements made by the applicant proved to be false, and that performance was at least satisfactory. A reference interview might be 'not clear' because of embellished responsibilities, inaccurate dates of employment, exaggerated titles claimed for position held, internal theft, poor performance, or a variety of other unfavorable indicators.

\section{Criminal Record Check}

A criminal record check is clear when the applicant has no criminal convictions. Criminal record checks are 'not clear' when the applicant has had criminal convictions. Criminal records encompass anything from driving under the influence or disturbing the peace to assault or murder. Research suggests that $5 \%$ of applicants in the US have a criminal record (Hight \& Raphael, 2003; Wiggins, 1998). In the UK, "31\% of men have criminal records by the time they are 40 " (Trades Union Congress, 2001). A recent study has revealed a strong correlation between criminal records and poor performance (Hight \& Raphael, 2003). 


\section{Credit Bureau Investigation}

Another screening tool that provides useful information is a credit bureau investigation, which can alert a company to patterns of behavior that include bankruptcies, foreclosures, or defaults on payments or loans. According to Wiggins (1998), approximately half of job applicants have poor credit ratings. Credit bureau investigations can also be used to verify identification information (Rosen, 2005, 205). These investigations provide personal data such as aliases or previous addresses that can reveal inconsistencies in the subject's history thus prompting further investigation.

\section{Education Verification}

Education verifications are 'clear' when the applicant has the educational history or certification that he/she claimed. For an applicant to be deemed 'not clear' through education verification, an important piece of information regarding their educational history or standing must be found to be false. This could be dates of attendance, grades earned or degrees received. According to some studies (Sloane, 1991; Rosen, 2002, Buckhoff, 2003), approximately $30 \%$ of education credentials include fraudulent information regarding degrees received, institutions attended, or professional memberships. This type of false information can leave a company open to negligent hiring litigation if the employee is found to have done harm to a coworker or a customer physically, financially, or emotionally.

Previous research focused on the percentage of applicants that were deemed 'not clear' based on individual screening tools (Hight \&Raphael, 2003; Wiggins, 1998; White, 1995). To our knowledge no previous research has focused on the percentage of 'not clear' applicants through comprehensive background checks, including the four tools, or any combination of these screening tools. The percentage of applicants found to be 'not clear' by individual screening tools cannot simply be totaled because this fails to account for overlap between screening tools. For example, when one applicant is deemed 'not clear' for both criminal record check and education verification there is only one applicant screened out.

Previous studies have also not identified the effects of cross-referencing information obtained from various screening tools. Cross-referencing occurs when an applicant, who would not be found 'not clear' based on any individual screening tool, is deemed 'not clear' because of inconstancies revealed by comparing the results of multiple screening tools. By examining screening tools as part of a comprehensive package it is possible to identify the effects of cross-referencing. The main contribution of this paper is to measure the cross-referencing effect in Canada.

\section{DESCRIPTIVE STATISTICS}

Data were obtained from BackCheck ${ }^{\mathrm{TM}}$, Canada's largest background checking company. As seen in Table 1, the sample included 142,946 applicants. These candidates applied for positions with the largest 127 Canadian companies in 2005, ranging from entry-level retail, customer service, to executive level management and engineering positions. These positions were in diverse industries including: retail, information and communications technology, mining, oil and gas extraction, utilities, agriculture and fisheries industry, manufacturing, administrative and support services, professional services, transportation and warehousing, entertainment and recreation, health care, accommodation and food service, and finance and insurance.

Each applicant underwent a background check using fourteen different combinations of the following four pre-employment screening tools; reference interviews, criminal record checks, credit bureau investigations, and education checks. Table 1 reports the total number of applicants screened by category of package and the percentage that each package represents.

As seen in Table 1, the three most common packages used are Criminal Check (48.85\%), Reference and Criminal (14.46\%) and Criminal and Credit (10.01\%). Individual tools represent 57.52\% of background verification requests while the combination packages represent $42.48 \%$. The objective of this paper is to show that the information obtained from the combination packages is more reliable than the information obtained through individual tools. 
Table 1: Number Of Applicants per Screening Tool

\begin{tabular}{lcc}
\hline Package & Number Of Applicants & Percentage \\
\hline Reference & 11,043 & $7.73 \%$ \\
Education & 122 & $0.09 \%$ \\
Criminal & 69,829 & $48.85 \%$ \\
Credit & 1,210 & $0.85 \%$ \\
Reference, Education & 5,374 & $3.76 \%$ \\
Reference, Criminal & 20,669 & $14.46 \%$ \\
Reference, Credit & 181 & $0.13 \%$ \\
Reference, Education, Criminal & 3,751 & $2.62 \%$ \\
Reference, Education, Credit & 103 & $0.07 \%$ \\
Reference, Criminal, Credit & 11,196 & $7.83 \%$ \\
Reference, Education, Criminal, Credit & 5,338 & $3.73 \%$ \\
Education, Criminal & 524 & $0.37 \%$ \\
Education, Criminal, Credit & 5,06 & $0.35 \%$ \\
Criminal, Credit & 14,311 & $10.01 \%$ \\
\hline
\end{tabular}

\section{Individual Screening Tools}

Summary data was calculated to determine the percent of applicants 'not clear' that each screening tool uncovered (See Table 2).

Table 2: Individual Screening Tools

\begin{tabular}{lcc}
\hline Package & Number of Applicants & Percentage of "Not Clear" \\
\hline Criminal & 69,829 & $4.72 \%$ \\
Education & 122 & $11.48 \%$ \\
Reference & 11,043 & $14.29 \%$ \\
Credit & 1,210 & $24.21 \%$ \\
\hline
\end{tabular}

As seen in Table 2, the largest percentage of 'not clear' (24.21\%) was uncovered through Credit Checks. However it is also intriguing that almost $12 \%$ of the applicants are not reporting accurate information regarding their education and $14 \%$ of the references are not positive.

\section{Packaged Screening Tools}

In Table 3, the percentage of 'not clear' is reported for each combination of screening tools. From Table 3, it is noticeable that the percentage of negative indicators uncovered varies directly with the number of screening tools used. For example, package 10 includes all four screening tools (reference check, criminal record check, education check, and credit bureau investigation) and identified $46.38 \%$ of applicants as 'not clear'. When only three screening tools were used (reference check, education check, and criminal record check), the percentage of applicants 'not clear' dropped to $30.50 \%$. When two screening tools (reference check and criminal record check) were used the number of applicants found to be 'not clear' dropped to $25.37 \%$. 
Table 3: Packaged Screening Tools

\begin{tabular}{clcc}
\hline & Package & Number of Applicants & \% of "Not Clear" \\
\hline 1 & Education, Criminal & 524 & $10.31 \%$ \\
2 & Criminal, Credit & 14,311 & $22.16 \%$ \\
3 & Reference, Education & 5,374 & $22.66 \%$ \\
4 & Reference, Criminal & 20,669 & $25.37 \%$ \\
5 & Reference, Credit & 181 & $38.67 \%$ \\
6 & Reference, Education, Criminal & 3,751 & $30.50 \%$ \\
7 & Education, Criminal, Credit & 506 & $30.50 \%$ \\
8 & Reference, Education, Credit & 103 & $33.01 \%$ \\
9 & Reference, Criminal, Credit & 11,196 & $39.91 \%$ \\
10 & Reference, Education, Criminal, Credit & 5,338 & $46.38 \%$ \\
\hline
\end{tabular}

Table 4: Cross-Referencing Effect

\begin{tabular}{lcc}
\hline Package & Individual Tool & $\begin{array}{c}\text { Package: Reference, Education, } \\
\text { Criminal, Credit }\end{array}$ \\
\hline Reference - \% Not Clear & $14.00 \%$ & $24.00 \%$ \\
Education - \% Not Clear & $11.50 \%$ & $13.40 \%$ \\
Criminal - \% Not Clear & $4.70 \%$ & $6.09 \%$ \\
Credit - \% Not Clear & $24.20 \%$ & $21.10 \%$ \\
\hline
\end{tabular}

\section{MEASURING THE CROSS-REFERENCING EFFECT}

The previous two tables, (Tables 2 and 3) have shown that as more tools are used to screen employees, higher percentages of 'not clear' are found. Noteworthy is the fact that for each pre-employment screening tool, the percentage of 'not clear' is higher when the tool is used in combination with another tool. Please refer to Table 4.

The synergy effect of combining these screening tools arises from a process termed cross-referencing, which compares the information gathered from one screening tool to information from another. This comparison reveals missing or inconsistent information which can lead to the discovery of further negative indictors that would not normally be uncovered by any individual screening tool. An example of this occurs when a reference check and criminal record check are used in conjunction. The reference provided may not remember the applicant when phoned for a reference because the applicant had always used a nickname or alias. On the criminal record check, however, the applicant must include all aliases. When the correct applicant is identified, negative information is much more likely to be obtained. Another example occurs when credit bureau investigations are combined with reference interviews. The credit check can fill in gaps of the employment history that the applicant may wish to conceal.

Applicants have little reason to distort or conceal 'clear' employment histories, thus applicants who hide positions or information often do so to avoid exposure of negative indicators. Incidents such as these are much more common than many HR professionals realize. By utilizing combinations of pre-employment screening tools, the applicant is less able to conceal important information and the organization is able to acquire all relevant facts.

The following chart shows that when reference checks were used alone, $14.29 \%$ of applicants were determined to be 'not clear'. However, when references were used in conjunction with criminal record checks and credit bureau investigations, the number of references that were determined 'not clear' increased to $21.62 \%$. This is not including applicants who have been determined to be 'not clear' because of criminal record checks or credit bureau investigations. Further, when reference checks were used with all three other screening tools, criminal record checks, education verifications, and credit bureau investigations, the percent of references that were 'not clear' increased further to $23.85 \%$. Again, this does not include applicants who were 'not clear' because of their criminal, credit, or educational histories. 


\section{Number of 'Not Clear' Reference Interviews}

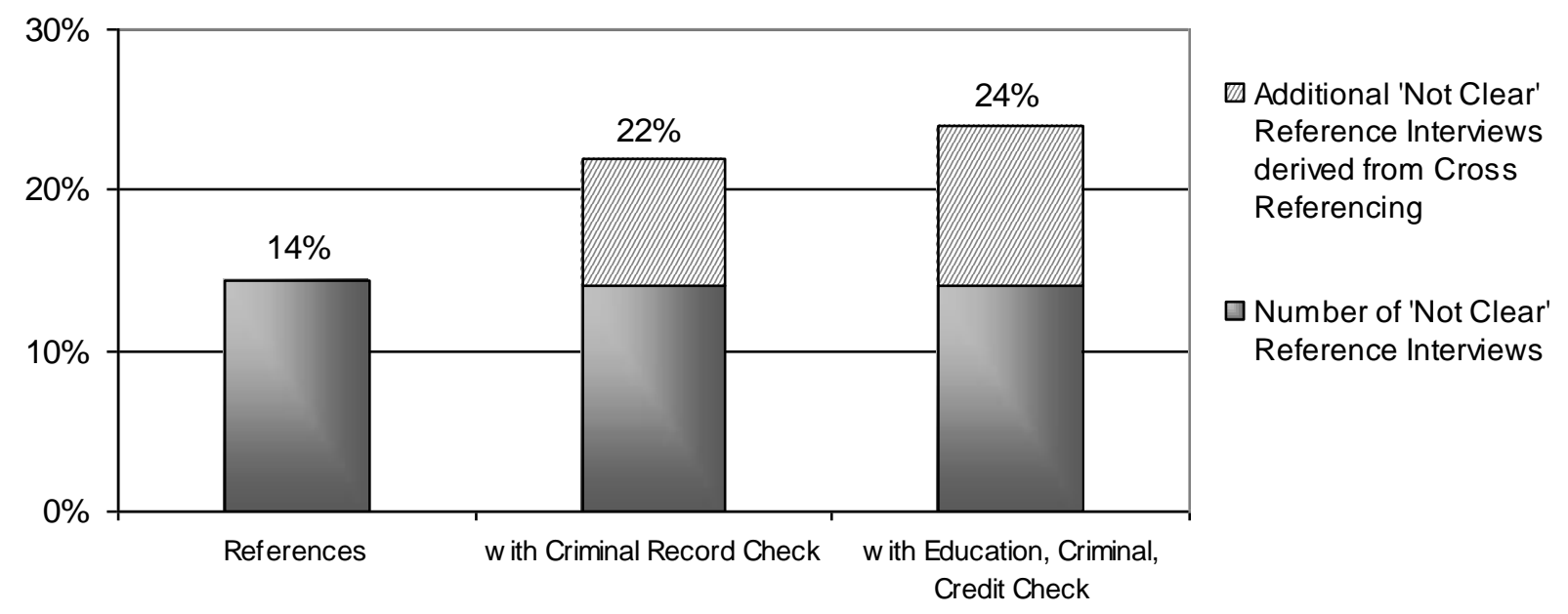

\section{CONCLUSION}

Previous research on the results of pre-employment background checks has focused primarily on applicants in the United States and Britain, while limited research has been conducted on applicants in Canada. This research fills this gap by showing that the 'not clear' rate of individual screening tools in Canada is in line with that previously published by American sources.

The second contribution of our research is to examine these screening tools in combination. Other research focuses on the percentages of applicants that are found to be 'not clear' through individual screening tools (Hight \& Raphael, 2003; Wiggins, 1998; White, 1995.) Thus far, no research has been conducted to evaluate the effects of combining screening tools into comprehensive packages.

Recognizing that screening tools work together as a package, two effects have been identified. First, the percentage of negative indicators uncovered varies directly with the number of screening tools used. The greater the number of screening tools used the larger the rate of 'not clear' reported. With only one screening tool, the weighted average of 'not clear' reported is $10.39 \%$ while with the four tools combined, the percentage reached $46.38 \%$. Second, a synergy, called the cross-referencing effect, occurs between screening tools. Cross-referencing allows uncovering information that would otherwise not have been uncovered. The findings of this research show that the use of a comprehensive background check, including reference interviews, criminal record checks, credit bureau investigations, and education verifications, decreases the risks of bad hires. This effect is well illustrated with reference interviews. When reference interviews are conducted in connection with other screening tools the rate of 'not clear' reference interviews increases by up to $10 \%$.

The cross-referencing effect has important implications for firms who outsource these duties. Firms who outsource their criminal record and/or credit bureau investigations, but retain reference interviews in-house, would likely be better served by allowing the whole process to be completed together to maximize the benefit of crossreferencing. When firms separate the conduct of these various screening tools, they obtain the overlap that occurs as each screening tool is used individually, but fail to obtain the benefit that occurs from cross-referencing. By outsourcing each of the screening steps the firm can acquire more value due to cross-referencing. These results indicate that combining screening tools as opposed to independent package screens out more applicants and provides more detailed and accurate background checks. 
The current work is deliberately exploratory. Collecting data on 142,946 applicants is a strength of this investigation. However the sample covers only one year and does not provide information by industry, by category of jobs and does not measure the benefits for the employees. Further research will fill these gaps. A forthcoming paper will measure the difference across industries in term of 'not clear' rate and will identify the optimal combination of screening tools per industry. In future research the return on investment (ROI) of background check will also be measured. Measuring the ROI will help professionals to make a decision regarding which tools to use on their applicant pool.

\section{REFERENCES}

1. Adler, S., (1993). Verifying a job candidate's background: The state of practice in a vital human resources activity. Review of Business. Vol. 15 (2) pg 3-8.

2. Buckhoff, T., (2003). Preventing fraud by conducting background checks. The CPA Journal. Vol. 73 (11) pg 52-56. Retrieved from ABI/Inform on February 7, 2006.

3. Frankenfield, G. and Kleiner, B., (2000). Effective employment screening practices. Management Research News. Vol. 23 (7/8). Pg 24-30. Retrieved from ABI/Inform on January 31, 2006.

4. Hight, D. and Raphael, A., (2003). Should housing departments conduct criminal background checks. Journal of College and University Student Housing. Vol.32 pg 10-15. Retrieved from Googlescholar on January 31, 2006.

5. $\quad$ Keller, S., (2004). Employee screening: A real-world cost/benefit analysis. Risk Management. Vol. 51 (11). Pg 28-32. Retrieved from ABI Inform on February 7, 2006.

6. Le, M. and Kleiner, B., (2000). Understanding and preventing negligent hiring. Management Research News. Vol. 23 (7/8). Retrieved from ABI/Inform on January 31, 2006.

7. Mesenbrink, J., (2002). Covering your back. Security. Vol. 39 (2) pg. 37. Retrieved from ABI/Inform on January 31, 2006.

8. Philbrick, J., Bart, B., Sparks, M., and Hass, M., (1999). Pre-employment screening: A decade of change. American Business Review. Pg 75-85. Retrieved from Googlescholar on January 31, 2006.

9. Rosen, L., (2005) The Safe Hiring Manual; The Complete Guide to Keeping Criminals, Terrorists, and Imposters Out of Your Workplace. Tempe. Facts on Demand Press.

10. Sanford, J., (2005). Making cents out of the hiring process. Strategic Finance. Vol. 87 (6). Retrieved from Business Source Premier on January 31, 2006.

11. Sloane, A., (1991). Countering resume fraud within and beyond banking: No excuse for not doing more. Labor Law Journal. Pg 303-310. Retrieved from ABI/Inform on January 31, 2006.

12. Trades Union Congress (2001) Employment and Ex-offenders. Retrieved from Google Scholar May 11, 2006

13. Vinik, F., (2005). Why background checks matter in academe. Chronicle of Higher Education. Vol. 51 (38) pg. B13, 4pgs. Retrieved from Academic Search Elite on February 7, 2006.

14. Wang, J. and Kleiner, B., (2004). Effective employment screening practices. Management Research News. Vol. 27 (4/5) pg 99-107. Retrieved from ABI/Inform on February 7, 2006.

15. Wiggins, D., (1998). Always check'em out first. Journal of Environmental Health. Vol. 61 (3) pg 61-63. Retrieved from Academic Search Elite on February 7, 2006.

16. White, G. (1995). Employee Turnover: The Hidden Drain on Profits. HR Focus. Vol. 72, (1) pg. 15, 3 pgs 


\section{NOTES}

